\title{
Refractory Primary Peritoneal Carcinoma
}

National Cancer Institute

\section{Source}

National Cancer Institute. Refractory Primary Peritoneal Carcinoma. NCI Thesaurus.

Code C152046.

Primary peritoneal carcinoma that is resistant to treatment. 